04

\title{
Короткий разряд с термоэмиссионным катодом в парах щелочноземельных металлов
}

\author{
(C) А.А. Богданов, В.Б. Каплан, А.М. Марциновский \\ Физико-технический институт им. А.Ф. Иофрфе РАН, \\ 194021 Санкт-Петербург, Россия \\ ฯ e-mail: amartsinovsky@gmail.com
}

(Поступило в Редакцию 25 мая 2017г.)

\begin{abstract}
Приведены результаты исследования короткого (без положительного столба) кнудсеновского термоэмиссионного разряда в парах бария и стронция. Анализ результатов показал, что основные закономерности этих разрядов и механизм их поддержания - эффективный разогрев катодным электронным пучком электронов плазмы, осуществляющих ступенчатую ионизацию - близки к таковым для разряда в цезии.
\end{abstract}

DOI: 10.21883/JTF.2018.06.46010.2361

Короткий термоэмиссионный разряд в связи с проблемами термоэмиссионного преобразования (ТЭП) всесторонне исследован для цезия [1], менее подробно, но тоже достаточно полно - для ксенона [2,3]. Оказалось, что радикальное изменение сечений элементарных процессов при переходе от атома Cs к атому Хе и большие различия в потенциалах ионизации и схеме энергетических уровней этих атомов не только количественно, но и качественно влияет на физическую картину и закономерности термоэмиссионного разряда. Поэтому представляло большой интерес исследовать разряд в щелочноземельных металлах - барии и стронции, атомы которых обладают сходной с цезием схемой энергетических уровней, которая характеризуется низким потенциалом ионизации (для $\mathrm{Cs}, \mathrm{Ba}, \mathrm{Sr}$ соответственно 3.89 , $5.21,5 / 69 \mathrm{eV})$, низколежащим резонансным уровнем (1.4, $1.52,1.78 \mathrm{eV})$ с достаточно равномерно сходящимися к пределу верхними возбужденными уровнями, а также относительно близкими сечениями элементарных процессов (рассеяние электронов, возбуждение и ионизация).

Как показал опыт исследований Cs-Ba ТЭП, их главная трудность связана с высокой агрессивностью бария и высокими температурами его резервуара (900-1000 K), необходимыми для создания давлений $\sim 10^{-2}$ Torr, обеспечивающих высокую (десятки $\mathrm{A} / \mathrm{cm}^{2}$ ) эмиссию катода, что требует сложной экспериментальной установки [4]. Нам удалось обойти эту трудность, создав прибор с негерметично капсулированным разрядным промежутком, в котором весь разрядный узел помещался в откачиваемую стеклянную колбу. Катодом и анодом служили торцы соосных молибденовых цилиндров диаметром $6 \mathrm{~mm}$, на которые надевалась цилиндрическая бериллиевая керамика с отверстием (закрываемым сапфировой пластинкой) для наблюдения за разрядом. В аноде вытачивалась полость с крышкой, куда помещались кусочки Ва или $\mathrm{Sr}$ в железной трубочке. В торце анода просверливалось несколько отверстий диаметром $\sim 1 \mathrm{~mm}$, через которые пары щелочного металла поступали в разрядный промежуток. Катод был полый с косвенным подогревом [1]. Нагрев анода осуществлялся танталовой фольгой, обернутой снаружи керамики, температура анода $T_{a}$ задавала давление $p$ и определялась термопарой. Фактически через межэлектродный промежуток проходил слабый поток паров, которые выходили сквозь щели между керамикой и электродами и высаживались на более холодной колбе. Площадь отверстий в торце анода $\left(\sim 5 \mathrm{~mm}^{2}\right)$ на порядок превышает площадь щелей, поэтому отклонение давления от равновесного значения не было большим.

Для минимизации разогрева анода током при измерениях с $p=$ const снятие вольт-амперных характеристик (BAX) разряда проводились в импульсном режиме на низкой частоте повторения импульсов $(\sim 100 \mathrm{~Hz})$ и при их минимальной длительности, обеспечивающей выход разрядной плазмы в стационарное состояние ( 50-100 $\mu \mathrm{s})$.

На рис. 1, а приведено типичное семейство ВАХ бариевого разряда; аналогичные характеристики получены и для стронциевого разряда. В исследованной области низких давлений ВАХ для $\mathrm{Ba}$ и $\mathrm{Sr}$, как и ВАХ кнудсеновского разряда в цезии, имеют вертикальный участок при напряжении гашения $U_{q}$ и участок насыщения, который определяется в основном увеличением тока эмиссии с ростом катодного скачка потенциала $\varphi_{k}$ и поля на катоде при увеличении анодного напряжения. Эффект Шоттки при $p \sim 10^{-2}$ Torr увеличивает проходящий ток в 1.5-2 раза по сравнению с током эмиссии катода при нулевом поле $j_{s}^{0}$, причем основное увеличение тока происходит в окрестности точки излома ВАХ. При дальнейшем увеличении анодного напряжения $U_{a}$ и переходе плазмы в состояние полной ионизации эффект Шоттки практически насыщается, с этим и связано образование участка насыщения тока; по величине тока в точке излома ВАХ можно определить эмиссионные свойства материала катода в парах щелочноземельных металлов. В исследованном диапазоне давлений $\left(10^{-3}-10^{-1}\right.$ Torr $)$ и температур катода $(1450-1800 \mathrm{~K})$ вблизи максимума $S$-образных кривых работа выхода молибдена в па- 

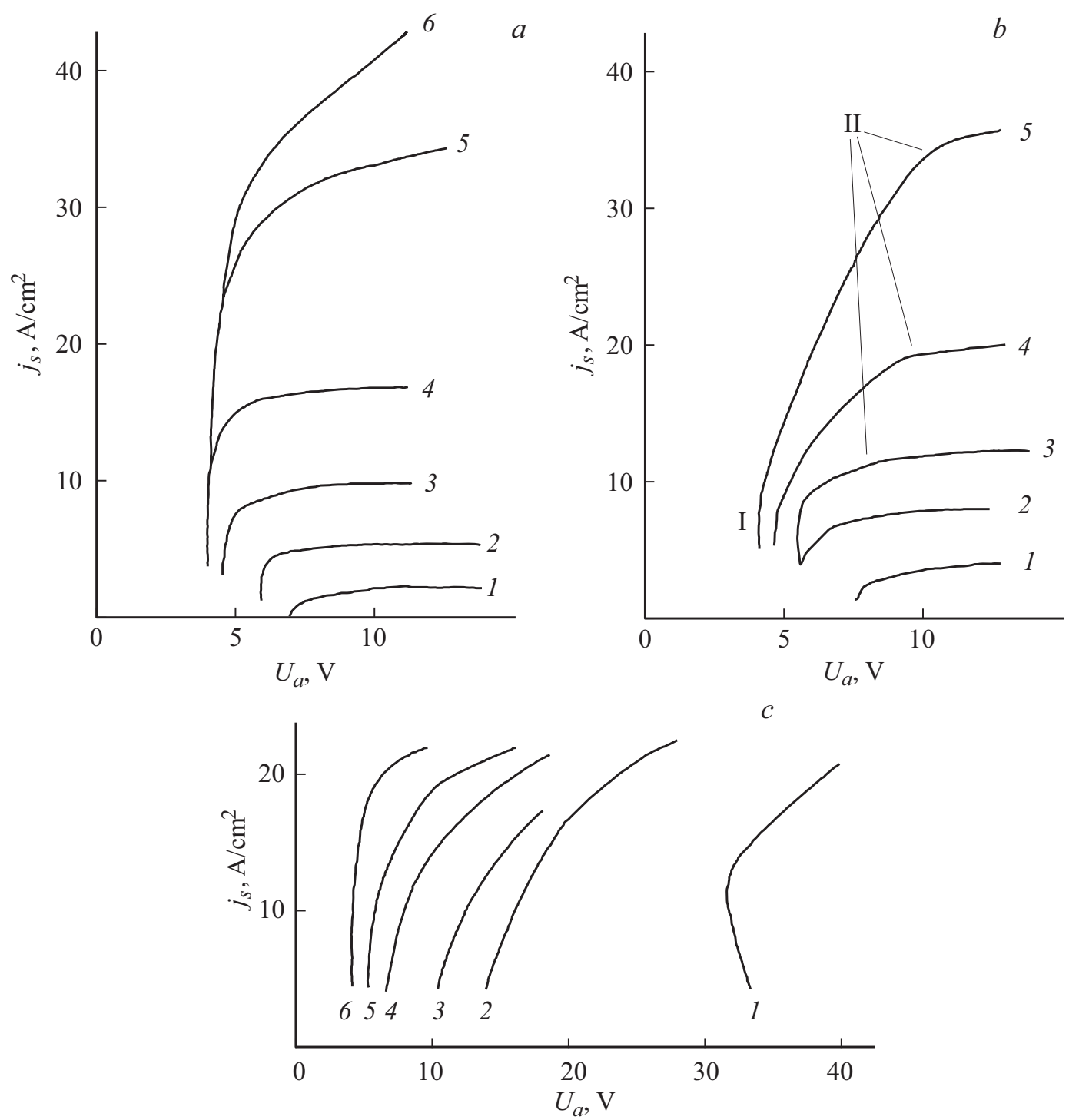

Рис. 1. ВАХ разряда в барии. Межэлектродное расстояние $d=0.2-0.3 \mathrm{~mm} . a-p=6.5 \cdot 10^{-2}$ Torr, $T_{k}, \mathrm{~K}: 1-1513,2-1565$, $3-1610,4-1656,5-1732,6-1765 ; b-p=4.1 \cdot 10^{-2}$ Torr, $T_{k}, \mathrm{~K}: 1-1545,2-1600,3-1635,4-1673,5-1740$; $c-T_{k}=1665 \mathrm{~K}, p \cdot 10^{-2}$ Torr: $1-3.2,2-3.7,3-4.2,4-4.9,5-5.5,6-6.6$.

pax бария составила 2.4-2.5eV, в парах стронция $2.5-2.7 \mathrm{eV}$ (отношение температур катода и анода $T_{k} / T_{a}$ в обоих случаях составляло 1.8-2.2).

При уменьшении давления до $4.1 \cdot 10^{-2}$ Torr на BAX бариевого разряда появляется существенная особенность (рис. $1, b)$ : образуются две точки излома I и II. $\mathrm{C}$ ростом $T_{k}$ и $j_{s}$ здесь после первой точки излома I возникает наклонный участок (кривые $3-5$ ). С ростом $T_{k}$ ток в первой точке излома практически не меняется, увеличивается только протяженность наклонного участка, следовательно, увеличивается и ток во второй точке излома II, после которой BAX выходят на участок насыщения. Появление участка с большим наклоном и второй точки излома наблюдалось ранее на ВАХ цезиевой дуги при больших давлениях ( $p d>0.1$ Torr $\cdot \mathrm{mm}$, $d$ - межэлектродное расстояние) и токах эмиссии $\left(j_{s} \gtrsim 10 \mathrm{~A} / \mathrm{cm}^{2}\right)$. Эти особенности объяснялись возникновением виртуального катода на наклонном участке [5]. Виртуальный катод ограничивает ток и обусловлен невысокой скоростью генерации ионов на вертикальном участке BAX, недостаточной для полной компенсации большой плотности тока эмиссии $j_{s}^{0}$. Скорость генерации определяется ступенчатой ионизацией электронами плазмы, которым передается энергия катодного пучка электронов за счет парных кулоновских столкновений или за счет коллективных процессов [6]. При увеличении $U_{a}$ выше $U_{q}$ скорость генерации и ток быстро растут, виртуальный катод при этом уменьшается и исчезает, после чего происходит уже более медленный рост тока, вызванный эффектом Шоттки. Поэтому при исчезновении виртуального катода на ВАХ образуется вторая точка излома, ток в которой примерно равен 
току эмиссии. Можно с полным основанием считать, что и в приборе с бариевым наполнением в режимах, где на BAX наблюдается наклонный участок и две точки излома, также образуется виртуальный катод. Эффект Шоттки играет существенную роль при больших давлениях, при малых давлениях его влияние уменьшается, поэтому в бариевом разряде за второй точкой излома наблюдается участок почти полного насыщения тока.

На режимы с виртуальным катодом может в принципе сильно влиять захват ионов в прикатодную яму. Однако исследования предподжиговых режимов при низких давлениях [7] показали, что в случае пятнистых катодов и при малой глубине потенциальной ямы $\left(q \Delta \varphi_{k}<2-3 k T_{k}\right)$ велики надбарьерные потери захваченных ионов, здесь $\Delta \varphi_{k}$ - прикатодный барьер, $q-$ заряд электрона. Поэтому влияние захвата ионов значительно меньше расчетного для однородных катодов. Этот вывод полностью относится и к режимам с виртуальным катодом, поскольку средняя высота прикатодного барьера $q \Delta \varphi_{k}$ здесь невелика: $q \Delta \varphi_{k}<k T_{k} \ln \left(j_{2} / j_{1}\right)$ (где $j_{1}$ и $j_{2}$ - токи в первой и второй точках излома ВАХ), a толщина прикатодного слоя гораздо меньше длины свободного пробега иона.

Режимы с виртуальным катодом в цезии при уменьшении давления исчезают, поскольку с уменьшением давления до $p \sim 10^{-2}$ Torr эмиссия уменьшается до нескольких $\mathrm{A} / \mathrm{cm}^{2}$. Концентрация плазмы у электродов при этом не падает столь же сильно вследствие увеличения температуры электронов $T_{e}$ и более однородного распределения ее по зазору. В щелочноземельных металлах эмиссия в максимуме $S$-образной кривой существенно выше, чем в цезии, поэтому режимы с виртуальным катодом здесь можно наблюдать и при сравнительно низких давлениях, как это видно из рис. $1, b$.

Отметим, что в исследованном диапазоне давлений в приборе со стронцием отсутствовали режимы с виртуальным катодом. Такое различие режимов в приборах с бариевым и стронциевым наполнением связано с тем, что зазор в бариевом приборе был примерно в I0 раз меньше, чем в приборе со стронцием. В приборе с узким зазором при одинаковых давлениях сохраняется большая эмиссия, а эффективность ионизации падает, что создает наиболее благоприятные условия для появления виртуального катода. На рис. 1, $c$ видно образование наклонного участка BAX с виртуальным катодом при постепенном уменьшении давления. С уменьшением $p$ растет длина наклонного участка, уменьшается ток в первой точке излома и увеличивается напряжение гашения $U_{q}$.

Напряжение гашения $U_{q}$ является важной интегральной характеристикой разряда, которая, с одной стороны, отражает процессы плазмообразования (генерацию и потерю ионов) при минимально возможном энерговкладе в разряд. С другой стороны, оно определяет существенные характеристики технических устройств, использующих данный вид разряда. Наиболее сильно на величину $U_{q}$ влияют параметр $p d$ и ток эмиссии катода.

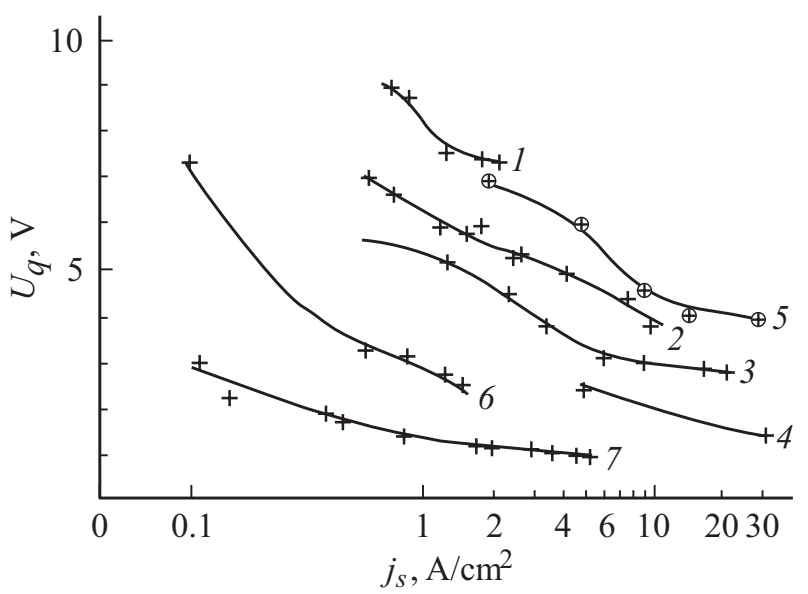

Рис. 2. Напряжение гашения $U_{q}$ термоэмиссионных разрядов в разных средах в зависимости от тока эмиссии катода $j_{s}$ для разных значений параметра $p d .1-4-$ стронций, $d=3 \mathrm{~mm}$, pd $\cdot 10^{2}$ Torr $\cdot \mathrm{mm}: 1-0.9,2-(1.8-2.1), 3-(5-9), 4-42$; 5 - барий, $d \approx(0.2-0.3) \mathrm{mm}, p=6.5 \cdot 10^{-2}$ Torr; $6-7-$ цезий, $d=1 \mathrm{~mm}, p d \cdot 10^{2}$ Torr $\cdot \mathrm{mm}: 6-0.2,7-1.3$.

На рис. 2 приведены зависимости $U_{q}\left(j_{s}\right)$ для $\mathrm{Ba}, \mathrm{Sr}$ и для сравнения - Cs, полученные при постоянных давлениях. Так как при изменении температуры катода (за счет чего менялась эмиссия) менялся и температурный режим анода, давление поддерживалось не столь точно, как в приборах с жидкой фазой металла, помещаемой в специальный термостат. Поэтому для режимов, где давление заметно менялось, указан диапазон изменения.

Из рисунка видно, что при увеличении $j_{s}$ и $p d$ напряжение гашения стронциевой дуги уменьшается аналогично цезиевой - при увеличении $p$ соответствующие кривые $1-4$ монотонно и достаточно равномерно смещаются вниз, как и для цезия (кривые 6, 7 этого же рисунка). Уменьшение $U_{q}$ с ростом $j_{s}$ и $p d$ объясняется увеличением эффективного сечения ионизации вследствие уменьшения относительной роли излучательных переходов [8]. Кроме того, при $p d>I 0^{-2}$ Torr $\cdot \mathrm{mm}$, когда длина свободного пробега ионов $l_{i a} \leq d$, рост давления уменьшает потери ионов на электроды, а также усиливает релаксацию катодного пучка на неупругих столкновениях с возбуждением резонансного уровня.

При одинаковых условиях для стронция $U_{q}$ значительно выше, чем для цезия. Так, для $j_{s}=5 \mathrm{~A} / \mathrm{cm}^{2}$ и $p d=(1.5-2) \cdot 10^{-2}$ Torr $\cdot \mathrm{mm}$ соответствующие значения равны 5 и $1 \mathrm{~V}$. Как видно из рис. 2, для цезия при $j_{s}=(5-10) \mathrm{A} / \mathrm{cm}^{2}$ зависимость $U_{q}\left(j_{s}\right)$ выходит практически на насыщение, причем для $p d \cdot 10^{2}=1.3$ Torr $\cdot \mathrm{mm}$ $U_{U}$ составляет всего $\sim 1 \mathrm{~V}$ (падение напряжения на межэлектродном промежутке при оптимальном $p d$ может уменьшаться до $0.4-0.5 \mathrm{~V}$ [1]). В стронции при $j_{s}=(5-30) \mathrm{A} / \mathrm{cm}^{2}$ наблюдается еще значительное уменьшение $U_{q}$. Поэтому при больших токах и оптимальных $p d$ напряжение гашения стронциевой дуги может быть также очень малым ( 1.5 V, рис. 2, кривая 4). 
Последнее обстоятельство может иметь и существенное практическое значение для проблемы высокотемпературных и радиационно-стойких плазменных сеточных ключей для инвертирования постоянного выходного напряжения космических термоэмиссионных реакторовпреобразователей, которая продолжает оставаться актуальной [9]. В последнее время установлено, что для цезиевых плазменных ключей ограничение рабочих давлений уровнем $\sim 10^{-2}$ Torr носит принципиальный характер и обусловлено прямой ионизацией атомов Cs в ячейках сетки [10]. Это ограничивает эмиссию катода (а значит, и модулируемые токи) несколькими $\mathrm{A} / \mathrm{cm}^{2}$ для самых эффективных катодных материалов. Использование стронциевого разряда в принципе может при тех же давлениях обеспечить на порядок большие токи при не слишком большом увеличении прямого падения напряжения на ключе.

Экспериментальных данных для разрядов в барии меньше, но в целом можно сделать вывод, что $U_{q}$ для разрядов в барии и стронции очень близки (рис. 2, кривая 5).

Таким образом, определены общие закономерности поведения BAX и влияние тока и давления на минимальное напряжение горения разряда в барии и стронции. Это позволило сделать вывод о том, что в коротких кнудсеновских разрядах с термоэмиссионным катодом в атомарных плазмообразущих средах с достаточно близкими (к цезию) сечениями элементарных процессов и сходной схемой энергетических уровней атомов в целом механизм поддержания разряда сохраняется неизменным.

\section{Список литературы}

[1] Термоэмиссионные преобразователи и низкотемпературная плазма / Под ред. Б.Я. Мойжеса и Г.Е. Пикуса. М.: Наука, 1973. $480 \mathrm{c}$.

[2] Бакшт Ф.Г., Иванов В.Г. // ЖТФ. 1980. Т. 50. Вып. 3. C. $471-480$.

[3] Баньковский Н.Г., Богданов А.А., Марциновский А.М. и др. // ЖТФ. 1983. Т. 53. Вып. 3. С. 1272-1279.

[4] Бабанин В.И., Дунаев Ю.А., Мустабаев А.С. и др. // ЖТФ. 1972. Т. 42. Вып. 8. С. 1662-1667.

[5] Дюжев Г.А., Марциновский А.М., Пикус Г.Е. и др. // ЖТФ. 1967. Т. 37. Вып. 10. С. 1825-1839.

[6] Бакшт Ф.Г., Богданов А.А., Каплан В.Б. и др. // Физика плазмы. 1981. Т. 7. Вып. 3. С. 547-559.

[7] Богданов А.А., Марциновский А.М. // ЖТФ. 1986. Т. 56. Вып. 9. С. 1825-1839.

[8] Бакшт Ф.Г., Дюжев Г.А., Каплан В.Б. и др. // ЖТФ. 1977. Т. 47. Вып. 2. С. 263-273.

[9] Ярыгин В.И. // Изв. вузов. Ядерная энергетика. 2013. Вып. 2. C. 5-27.

[10] Марциновский А.М., Столяров И.И. // Материалы Всерос. конф. по физике низкотемпературной плазмы. ФНТП2014. Казань. 2014. Т. 1. С. 110-114. 